\title{
Seroprevalence of Cytomegalovirus Infection and Associated Risk Factors among Human Immunodeficiency Virus Infected Patients Attending Thika Level 5 Hospital, Kenya
}

\author{
Nchagwa Edward Mangare, Margaret W. Muturi, George Gachara \\ Department of Medical Laboratory Science, Kenyatta University, Nairobi, Kenya \\ Email: mangarezeddy@yahoo.com,muturi.margaret@ku.ac.ke,ggachara@gmail.com
}

How to cite this paper: Mangare, N.E., Muturi, M.W. and Gachara, G. (2018) Seroprevalence of Cytomegalovirus Infection and Associated Risk Factors among Human Immunodeficiency Virus Infected Patients Attending Thika Level 5 Hospital, Kenya. Open Journal of Immunology, 8, 1-12.

https://doi.org/10.4236/oji.2018.81001

Received: February 11, 2018

Accepted: March 28, 2018

Published: March 31, 2018

Copyright $\odot 2018$ by authors and Scientific Research Publishing Inc. This work is licensed under the Creative Commons Attribution International License (CC BY 4.0).

http://creativecommons.org/licenses/by/4.0/

\begin{abstract}
Cytomegalovirus (CMV) is an important pathogen in immunocompromised individuals. Coupled with Human Immunodeficiency Virus (HIV), it causes end organ diseases leading to increased morbidity and mortality in the population. The prevalence of Cytomegalovirus infection is above 93\% in HIV infected children in Kenya. Despite, a high Cytomegalovirus seroprevalence found in children, few studies have documented CMV in adults. This study was done to determine the seroprevalence of CMV infection and its associated risk factors among HIV patients attending Thika level 5 Hospital in Kiambu County, Kenya. The study also evaluated the effect CMV infection on the immunity of HIV infected patients. A cross-sectional study involving $163 \mathrm{HIV}$ positive participants from different age groups was carried out. A questionnaire was used to assess the socio-demographic and specific risk factors associated with cytomegalovirus. Blood was collected and analyzed for CD4 counts, CMV IgG and IgM. The seroprevalence of CMV was found to be $89 \%$ (CMV IgG) while the incidence was $10.4 \%$ (CMV IgM). The study found that CMV infection leads to more suppression of the immunity among the HIV infected patients. In addition, education, economic status, having other sexual transmitted infections, sharing drinks, immune status and blood transfusion were associated with CMV infection ( $\mathrm{p}<0.05)$. The study recommends adoption of CMV screening services and education on CMV risk factors as CMV infection preventive strategies.
\end{abstract}

\section{Keywords}

Cytomegalovirus, Human Immunodeficiency Virus, Immunoglobulin G and $\mathrm{M}$ 


\section{Introduction}

Cytomegalovirus (CMV) is a ubiquitous virus commonly infecting people of all age groups, gender and race. Worldwide, CMV burden is high with exposure rates between $40 \%-100 \%$ [1]. In immunocompetent individuals, CMV exists in a symbiotic equilibrium and thus disease manifestations are rarely encountered [2]. However, in immunocompromised persons such as patients with Human Immunodeficiency Virus (HIV), neonates or through iatrogenic means following organ transplantation, CMV exerts its full pathogenic potential [3]. Human Immunodeficiency Virus infects CD4 T-Helper cells that regulate humoral and cellular immunity resulting to a weakened immune system [4]. After primary infection, CMV disperses and becomes latent in multiple organs and due to immunosuppression for example in HIV patients, CMV reactivation occurs [5]. Human cytomegalovirus has become a major public health problem throughout the world since its discovery.

Kenya has the fourth largest HIV epidemic in the world. By 2015, an estimate of 1.8 million Kenyans was living with HIV [6]. In 2003, only 6000 people living with HIV were accessing antiretroviral (ARV) therapy but by 2015 the number increased to 900,000 . In the absence of highly active antiretroviral therapy (HAART), patients with $\mathrm{CD} 4^{+}$cell counts below 100 cells/ $\mu \mathrm{l}$ are at a high risk of CMV associated retinitis, gastrointestinal and neurologic disease [7]. In the pre-HAART era, CMV end organ diseases among patients with advanced HIV infection were above $40 \%$. With the advent of HAART, the incidence of CMV end organ diseases (EODs) has reduced by $5 \%$ to $10 \%$ [8]. Currently, information on the prevalence of CMV and associated risk factors are scanty. There are two published studies on CMV infection among HIV patients in Kenya. In a study conducted at Nyumbani Children's Home, Nairobi, viral co-infections among children infected with HIV-1 were evaluated. There was 100\% CMV seroprevalence found in the 71 children of median age 2.2 years [9]. Another study conducted at Kenyatta National Hospital aimed at studying the kinetics of CMV replication in HIV infants [10]. At the third month of life CMV DNA was detected in $93 \%$ of infants who were HIV infected at birth and $90 \%$ in HIV exposed infants (born by HIV infected mother) who were uninfected. These two studies did not evaluate the risk factors associated with CMV acquisition among HIV patients. They also did not factor in the reactivation of CMV among HIV patients and also failed to consider the exposure rates in different age groups. Recently a high seroprevalence of CMV among pregnant women attending Thika level 5 Hospital was reported [11].

This study sought to determine the prevalence of CMV infection among HIV infected patients across different age groups. The study also evaluated the exposure rates; past, present and reactivation and the effect of CMV infection on the immunity of HIV infected patients.

\section{Methods}

A cross-sectional study involving one hundred and sixty three (163) HIV posi- 
tive patients from different age groups attending comprehensive care clinic at Thika level 5 Hospital, Kiambu County between November 2017 to January 2018 were enrolled. Systematic random sampling technique was used to obtain the minimum sample size using the formula by Daniel, 1999. Patients who voluntarily agreed to provide blood sample and confirmed HIV positive after re-test were selected for the study. Written consent was obtained from all the participants, after full explanation of the study. Participation was voluntary, the benefits and risks if any was explained to the patients. Detailed history and information on socio-demographics and risk factors associated with CMV acquisition were obtained using a structured questionnaire (appendix I). $\mathrm{CD} 4^{+}$cell counts were determined immediately after blood collection using the BD FACS Count and CMV IgG and IgM specific antibodies were analyzed by an indirect ELISA (Human Diagnostics Worldwide, Germany). Statistical analysis was performed using Statistical Package for Social Sciences (SPSS) version 20 and a p value of $\leq 05$ was considered significant.

Ethical approval for the study was obtained from Kenyatta University Ethics Review Committee (Protocol number 51/615).

\section{Results}

\subsection{Study Participants}

Among 163 participants enrolled in this study 76 (46.6\%) were males and 87 (53.4) were females (male to female ratio $=1: 1.14$ ). The mean age of participants was 35.47. Majority of participants were above the age of 25 years (Figure 1).

Married participants constituted the largest group among the participants (54.6\%). Majority of the participants had attained primary education (62.3\%) and were low income earners (65.4\%). The participants who had formal employment were the least (20\%) (Table 1).

The mean $\mathrm{CD}^{+}$count of participants above 12 years was 401.36 cells $/ \mu \mathrm{L}$ and 597.42 cells $/ \mu \mathrm{L}$ for children below 12 years. Majority of the participants had moderate immune suppression (55.4\%) while 18.4\% having severe immune suppression with $36.2 \%$ having no immune suppression (Table 2).

\subsection{Seroprevalence and Risk Factors}

Out of the total of 163 HIV seropositive subject under the study, $117(71.8 \%)$ of them tested positive for Cytomegalovirus IgG antibodies while 5 (3.1\%) tested positive for cytomegalovirus IgM positive. The overall seroprevalence of CMV (Both CMV-IgG and IgM positive) among participants was 99.4\%. Ant-CMV IgG prevalence was found to be $89 \%$ while anti-CMV IgG was found to be $10.4 \%$.

Distribution of CMV antibodies across different socio-demographic groups among HIV infected participants are as illustrated in Table 3. Socio-demographic factors like education and economic status were significant risk factors among the participants. 
Risk factors for CMV acquisition distribution among participants are as illustrated in Table 4. Various exposure mechanisms including sharing drinks, blood transfusion, and other sexual transmitted infections were significant risk factors among the participants.

Table 1. Demographic variables of participants indicating the number (n) of individuals in each variable in percentage (\%).

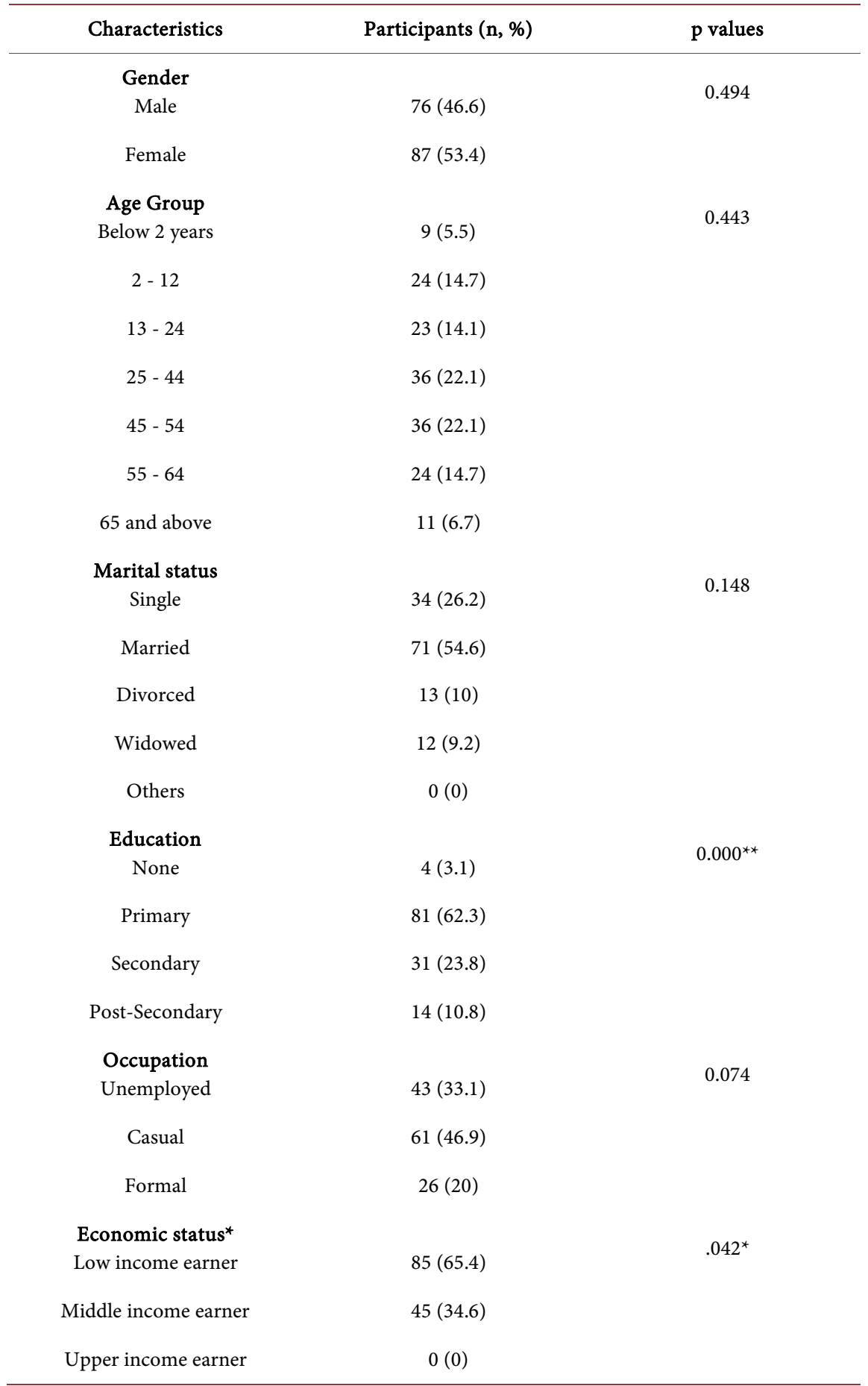

*(Monthly income < USD 236.7 low, > USD 236.71 - 1200 middle class, > USD 1200 upper). 
Table 2. The immune status (\%) across different age groups of HIV infected individuals. Moderate and severe immunosuppression was found in $45.4 \%$ and 18.4 respectively. There was no immune suppression in $36.2 \%$.

\begin{tabular}{ccccc}
\hline \multicolumn{5}{c}{ Immune category } \\
\hline Age group & $\begin{array}{c}\text { Participants } \\
(\mathrm{n})\end{array}$ & $\begin{array}{c}\text { No suppression } \\
(\mathrm{n}, \%)\end{array}$ & $\begin{array}{c}\text { Moderate } \\
\text { suppression } \\
(\mathrm{n}, \%)\end{array}$ & $\begin{array}{c}\text { Severe suppression } \\
\text { (n, \%) }\end{array}$ \\
\hline Below 2 years & 9 & $1(11.1)$ & $6(66.7)$ & $2(22.2)$ \\
$2-12$ & 24 & $11(45.8)$ & $10(41.7)$ & $3(12.5)$ \\
$13-24$ & 23 & $9(39.1)$ & $10(43.5)$ & $4(17.4)$ \\
$25-34$ & 17 & $8(47.1)$ & $7(41.2)$ & $2(11.8)$ \\
$35-44$ & 19 & $10(52.6)$ & $6(31.6)$ & $3(15.8)$ \\
$45-54$ & 36 & $13(36.1)$ & $18(50)$ & $5(13.9)$ \\
$55-64$ & 24 & $6(25)$ & $11(45.8)$ & $7(29.2)$ \\
65 and Above & 11 & $1(9.1)$ & $6(54.5)$ & $4(36.4)$ \\
Total & 163 & $59(36.2)$ & $74(45.4)$ & $\mathbf{3 0}(18.4)$
\end{tabular}

Table 3. The percentage distribution of Cytomegalovirus antibodies (IgG and IgM) across different socio-demographic groups among HIV infected individuals attending Thika level 5 Hospital.

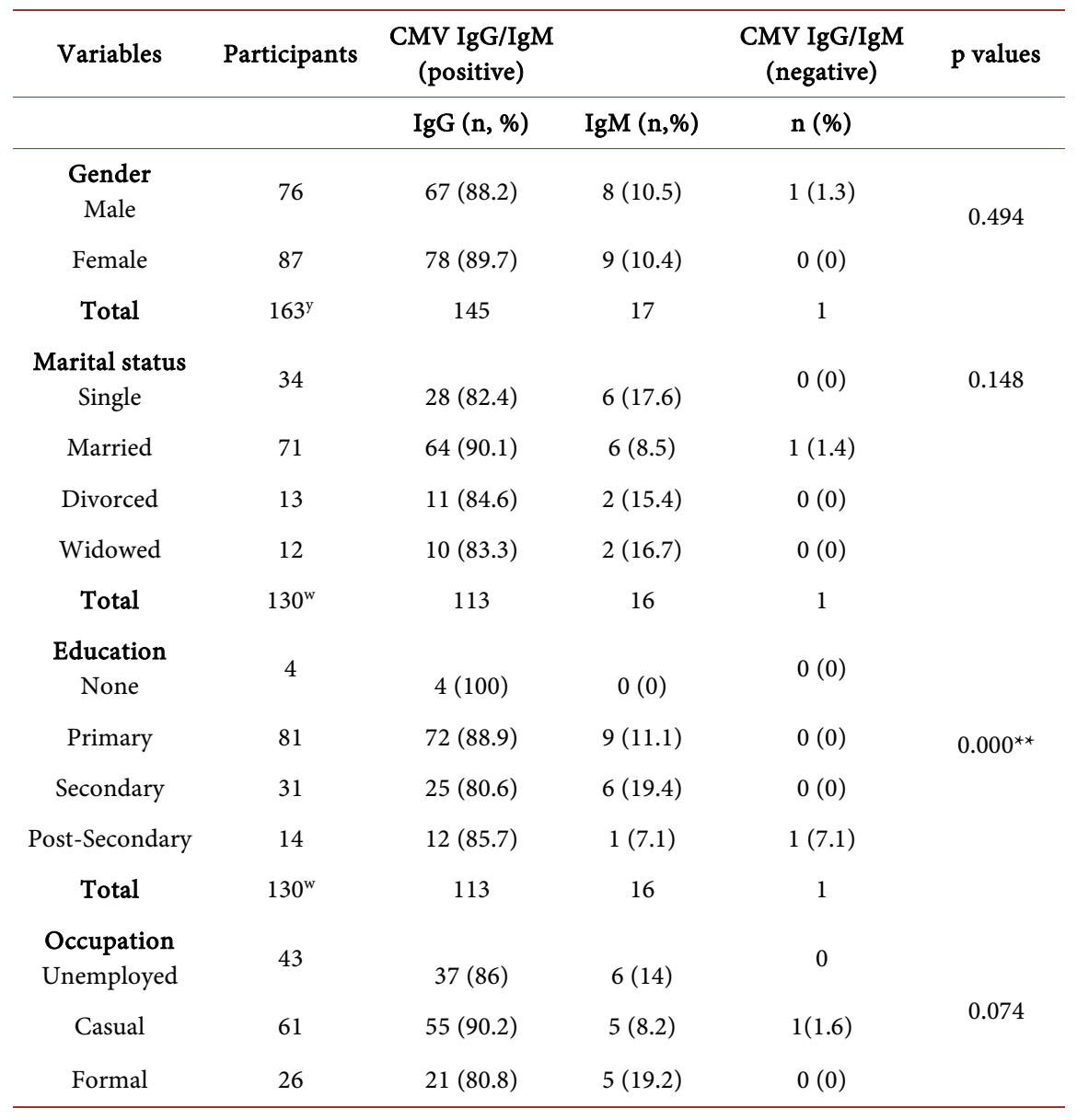




\section{Continued}

\begin{tabular}{lccccc}
\hline Total & $130^{\mathrm{w}}$ & 113 & 16 & 1 & \\
$\begin{array}{c}\text { Economic status } \\
\text { Low income } \\
\text { earner }\end{array}$ & 84 & $74(88.1)$ & $10(11.9)$ & $0(0)$ & \\
$\begin{array}{c}\text { Middle income } \\
\text { earner }\end{array}$ & 45 & $39(86.7)$ & $6(13.3)$ & $0(0)$ & $0.042^{*}$ \\
$\begin{array}{c}\text { Upper income } \\
\text { earner }\end{array}$ & 1 & $0(0)$ & $0(0.0)$ & $1(100)$ & \\
Total & $130^{\mathrm{w}}$ & 113 & 16 & 1 \\
\hline
\end{tabular}

${ }^{*} \mathrm{P}<0.01,{ }^{*} \mathrm{P}<0.05$. $\mathrm{y}$ indicates the total samples of both the children and adults while $\mathrm{w}$ indicates the total sample size for adults.

Table 4. Risk factors of individuals indicating their number (n) of subject in each variable and their statistical significance levels in form of $\mathrm{p}$ values.

\begin{tabular}{cccc}
\hline \multicolumn{1}{c}{ Risk factors } & Participants' n (\%) & p value \\
STI & Traditional & $53(40.7)$ & $0.041^{*}$ \\
Circumcision & Hospital & $16(25.4)$ & 0.072 \\
Group living habits & Camps, streets, inmates & $39(68.4)$ & 0.918 \\
Saliva sharing behaviours & and homecare & $4(3.1)$ & $0.042^{*}$ \\
& Sharing drinks & $125(76.7)$ & 0.054 \\
& Toothbrushes & $41(26.6)$ & 0.674 \\
Exposure to Children & Lip balm & $14(19.2)$ & 0.285 \\
Blood Transfusion & Kissing & $100(76.9)$ & 0.180 \\
\hline
\end{tabular}

${ }^{* *} \mathrm{P}<0.01,{ }^{*} \mathrm{P}<0.05$.

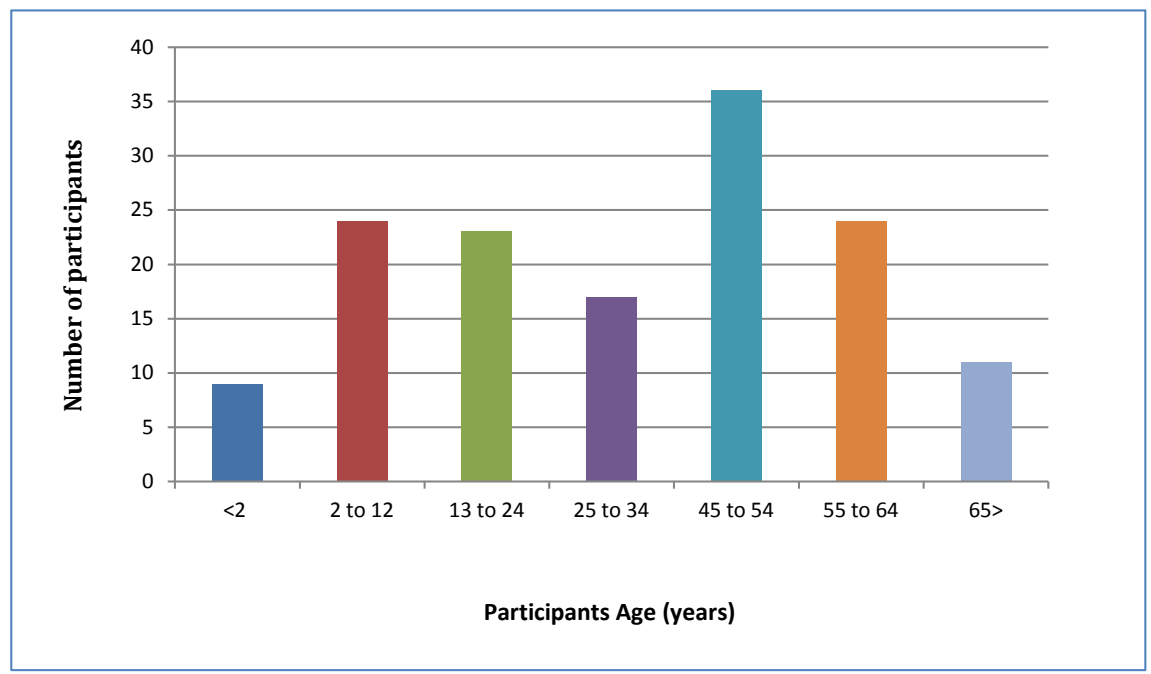

Figure 1. Age distribution of HIV infected individuals. 


\section{Discussion}

The seroprevalence of CMV infection among participants attending Thika level 5 Hospital was determined through detection of IgG and IgM antibodies. A high seroprevalence of anti-CMV IgG was found to be $89 \%$ among the participants. This is consistent with other investigations that have been previously reported; in Nigeria $100 \%$ among HIV patients [12], in Kenya 100\% among HIV-1 infected children at Nyumbani Children Home [9], 97\% among healthy blood donors at the National blood transfusion centre, Kenya [13], 87.9\% among volunteer blood donors in India [14] and 85\% among pregnant women at Thika level 5 hospital, Kenya [11].

Other countries like India, Sudan and Mali reported seroprevalences ranging from $89 \%$ - 97.5\% [15] [16] [17]. Nevertheless the seroprevalence results from this study were higher than the $46.8 \%$ obtained in France in pregnant women [17]. This may be ascribed to high hygiene standards observed [18]. Israel and eight European countries (France, Belgium, Spain, Italy, Germany, Austria, Portugal, and the Netherlands) do routine CMV serological screening of pregnant women [19]. Low CMV prevalence has been reported in these countries.

This study reported that $10.4 \%$ of the HIV seropositive patients were anti-CMV IgM seropositive indicating current infection or reinfection/reactivation to cytomegalovirus. This is consistent with a previous study among HIV patients in Nigeria that found an $11.1 \%$ anti-CMV IgM seroprevalence [20]. In another study in Brazil, anti-CMV IgM seroprevalence of $11.36 \%$ among HIV infected prison inmates was reported [21].

HIV immune suppressed patients have shown positive increase in $\mathrm{CD}^{+}$count when initiated on HAART for longer duration [22]. The high mean $\mathrm{CD}^{+}$count recorded in this study among the HIV infected patients could be as attributed to HAART since all the study participants were on HAART. Other studies has also showed that HAART has led to a recovery of patients immunity indicated by a rise in $\mathrm{CD}^{+}{ }^{+} \mathrm{T}$-lymphocytes count which leads to a reduction in AIDS related deaths [23]. This therefore has reduced the risk of end organ diseases.

A majority of the participants who were CMV positive had either moderate or severe immune suppression as compared to $36.2 \%$ who had no immune suppression. This shows that CMV and HIV synergy to down regulate the immune system among the co infected participants. A similar observation was made in Nigeria [20]. All the patients who had no formal education had a 100\% exposure to CMV indicating lack of awareness on basic risk factors and prevention mechanism due to lack of exposure to any form of education. Studies have shown that ignorance or lack of education is a factor that may lead to CMV acquisition [18].

Low economic status was strongly linked to CMV serostatus with majority of low income earners having acquired the virus. Low income earners more often practice unhealthy behaviors such as poor diet due to financial constrains that may lead to malnutrition thus low immune system. This can often lead to reac- 
tivation of CMV. Marital status and occupation had no association to CMV infection.

History of blood transfusion, history of sexual transmitted infections and sharing drinks were found to have a significant role in acquisition of CMV infection. Studies have previously shown that sexual transmitted infections are associated with CMV and HIV infection [24]. The findings on sharing drinks was however inconsistent to findings from a previous study that found that there was no differences in serostatus based on sharing of drinks [25]. While kissing and sharing drinks would mean sharing of saliva, sharing drinks was strongly linked to CMV infection unlike kissing. This finding is unclear though this could have been due to a relatively small sample size in the current study. Perhaps a further study with a larger sample size on this variable would be useful in clarifying this inconsistence.

Some of the limitations from this study were; limited sample size that might not have captured small differences among the groups and to evaluate differences in frequency of specific behaviors and some variables were constant among participants hence unable to assess their significance.

\section{Conclusion/Recommendation}

The seroprevalence and incidence of CMV were found to be $89 \%$ (CMV IgG) and $10.4 \%$ (CMV IgM) respectively. The high seroprevalence observed in this study is an indication of CMV endemicity in the study population. Education and low economic status showed a great association with CMV. Various exposure mechanisms including sharing drinks, blood transfusion, and other sexual transmitted infections play a great role in CMV acquisition; therefore, there is a need to adopt CMV screening services and education on CMV risk factors as CMV infection preventive strategies.

\section{Acknowledgements}

I would wish to acknowledge the management and the entire Thika Level 5 Hospital fraternity for their support throughout this journey.

\section{References}

[1] Mocarski, E.S., Shenk, T. and Pass, R.F. (2007) Cytomegalovirus. In: Knipe. D.M. and Howley, P.M., Eds., Fields Virology, 5th Edition, Lippincott Williams \& Wilkins, Philadelphia, 2701-2772.

[2] Griffiths, P.D. and Emery, V.C. (1997) Cytomegalovirus. In: Richman, D.D., Whitley, R.J. and Hayden, F.G., Eds., Clinical Virology, Churchill Livingstone, New York, 445-470.

[3] Mocarski (1993) Cytomegalovirus Biology and Replication. The Human Herpesviruses. Raven Press, New York, 173-226.

[4] Cheesbrough, M. (2005) Human Immunodeficiency Virus. In: District Laboratory Practice in Tropical Countries, 2nd Edition, Cambridge University Press, Cambridge, 253-255. 
[5] Hummel, M. and Abecassis, M.M. (2002) A Model for Reactivation of CMV from Latency. Journal of Clinical Virology, 25, 123-136.

http://www.sciencedirect.com/science/article/pii/S1386653202000884 https://doi.org/10.1016/S1386-6532(02)00088-4

[6] World Health Organization (2016) Global Aids up to Date. World Health Organization. Geneva 27 Switzerland.

[7] Salmon-Céron, D., Mazeron, M.C., Chaput, S., Boukli, N., Senechal, B., Houhou, N., et al. (2000) Plasma Cytomegalovirus DNA, pp65 Antigenaemia and a Low CD4 Cell Count Remain Risk Factors for Cytomegalovirus Disease in Patients Receiving Highly Active Antiretroviral Therapy. AIDS, 14, 1041-1049.

http://www.ncbi.nlm.nih.gov/pubmed/10853987 https://doi.org/10.1097/00002030-200005260-00017

[8] Wohl, D.A., Kendall, M.A., Andersen, J., Crumpacker, C., Spector, S.A., Feinberg, J., et al. (2009) Low Rate of CMV End-Organ Disease in HIV-Infected Patients Despite Low $\mathrm{CD}^{4+}$ Cell Counts and CMV Viremia: Results of ACTG Protocol A5030. HIV Clinical Trials, 10, 143-152. https://doi.org/10.1310/hct1003-143

[9] Chakraborty, R., Rees, G., Bourboulia, D., Cross, A.M., Dixon, J.R., D’Agostino, A., et al. (2003) Viral Coinfections among African Children Infected with Human Immunodeficiency Virus Type 1. Clinical Infectious Diseases, 36, 922-924.

http://cid.oxfordjournals.org/content/36/7/922.short https://doi.org/10.1086/368207

[10] Slyker, J.A., Lohman-Payne, B.L., John-Stewart, G.C., Maleche-Obimbo, E., Emery, S., Richardson, B., et al. (2009) Acute Cytomegalovirus Infection in Kenyan HIV-Infected Infants. AIDS, 23, 2173-2181. https://doi.org/10.1097/QAD.0b013e32833016e8

[11] Maingi, Z. and Nyamache, A.K. (2014) Seroprevalence of Cytomegalo Virus (CMV) among Pregnant Women in Thika, Kenya. BMC Research Notes, 7, 794.

http://www.biomedcentral.com/1756-0500/7/794/ https://doi.org/10.1186/1756-0500-7-794

[12] Akinbami, A.A., Akanmu, A.S., Adeyemo, T.A., Wright, K.O., Dada, M.O. and Dosunmu, A.O. (2010) Cytomegalovirus Antibodies amongst Immunocompromised (HIV) Patients at Lagos University Teaching Hospital (LUTH) Idi-Araba, Lagos. Journal of Medicine, 11, 151-154.

http://www.banglajol.info/index.php/JOM/article/viewArticle/5462 https://doi.org/10.3329/jom.v11i2.5462

[13] Njeru, D.G., Mwanda, W.O., Kitonyi, G.W. and Njagi, E.C. (2009) Prevalence of Cytomegalovirus Antibodies in Blood Donors at the National Blood Transfusion Centre, Nairobi. East African Medical Journal, 86, S58-S61. http://www.ncbi.nlm.nih.gov/pubmed/21591511

[14] Chaudhari, C.N. and Bindra, M.S. (2009) Seroprevalence of Cytomegalovirus among Voluntary Blood Donors. Medical Journal Armed Forces India, 65, 252-254. https://doi.org/10.1016/S0377-1237(09)80016-6

[15] Khairi, S.I., Intisar, K.S., Enan, K.H., Ishag, M.Y., Baraa, A.M. and Ali, Y.H. (2013) Seroprevalence of Cytomegalovirus Infection among Pregnant Women at Omdurman Maternity Hospital, Sudan. JMed. Lab Diagn., 4, 45-49.

[16] Izetiégouma Maïga, I., Tounkara, A., Coulibaly, G. and Kouriba, B. (2003) Seroprevalence of the Human Cytomegalovirus among Blood Donors and AIDS Patients in Bamako. Cahiers Sante.

http://resolver.lib.washington.edu/resserv?sid=EMBASE\&issn=11575999\&id=doi:\& $\underline{\text { atitle }=\text { Seroprevalence }+ \text { of }+ \text { the }+ \text { human }+ \text { cytomegalovirus }+ \text { among }+ \text { blood }+ \text { donors }+ \text { an }}$ 
$\underline{\mathrm{d}+\mathrm{AIDS}+\text { patients+in+Bama }}$

[17] Picone, O., Vauloup-Fellous, C., Cordier, A.G., Parent Du Châtelet, I., Senat, M.V., Frydman, R. and Grangeot-Keros, L. (2009) A 2-Year Study on Cytomegalovirus Infection during Pregnancy in a French Hospital. BJOG: An International Journal of Obstetrics and Gynaecology, 116, 818-823.

[18] Dowd, J.B., Aiello, E. and Alley, D.E. (2009) Socioeconomic Disparities in the Seroprevalence of Cytomegalovirus Infection in the US Population: NHANES III. Epidemiology and Infection, 137, 58-65. https://doi.org/10.1017/S0950268808000551

[19] Forsgren, M. (2009) Prevention of Congenital and Perinatal Infections. Eurosurveillance, 14, 2-4.

[20] Fowotade, A., Okonko, I.O., Agbede, O.O. and Suleiman, S.T. (2015) High Seropositivity of IgG and IgM Antibodies against Cytomegalovirus (CMV) among HIV-1 Seropositive Patients in Ilorin, Nigeria. African Health Sciences, 15, 1-9. https://doi.org/10.4314/ahs.v15i1.1

[21] Osti, N.M., Pestana De Castro, A.F. and Costallat Ricci, L. (1998) Research of Antigen and Antibodies from Retroviruses, CMV and HBV among Prisoners of the Penitentiary Complex of the Region of Campinas, SP, Brazil. Revista Do Instituto de Medicina Tropical de Sao Paulo, 40, 209-213. https://doi.org/10.1590/S0036-46651998000400001

[22] Lifson, A.R., Krantz, E.M., Eberly, L.E., Dolan, M.J., Marconi, V.C., Weintrob, A.C., Agan, B.K., et al. (2011) Long-Term CD4+ Lymphocyte Response Following HAART Initiation in a U.S. Military Prospective Cohort. AIDS Research and Therapy, 8, 2. https://doi.org/10.1186/1742-6405-8-2

[23] Mermin, J., Were, W., Ekwaru, J.P., Moore, D., Downing, R., Behumbiize, P., Bunnell, R., et al. (2008) Mortality in HIV-Infected Ugandan Adults Receiving Antiretroviral Treatment and Survival of Their HIV-Uninfected Children: A Prospective Cohort Study. The Lancet, 371, 752-759.

http://www.sciencedirect.com/science/article/pii/S014067360860345 https://doi.org/10.1016/S0140-6736(08)60345-1

[24] Clarke, L.M., Duerr, A., Feldman, J., Sierra, M.F., Daidone, B.J. and Landesman, S.H. (1996) Factors Associated with Cytomegalovirus Infection among Human Immunodeficiency Virus Type 1-Seronegative and -Seropositive Women from an Urban Minority Community. The Journal of Infectious Diseases, 173, 77-82. https://doi.org/10.1093/infdis/173.1.77

[25] Stadler, L.P., Bernstein, D.I., Callahan, S.T., Ferreira, J., Gorgone Simone, G.A., Edwards, K.M., Rosenthal, S.L., et al. (2010) Seroprevalence of Cytomegalovirus (CMV) and Risk Factors for Infection in Adolescent Males. Clinical Infectious Diseases. An Official Publication of the Infectious Diseases Society of America, 51, e76-e81. https://doi.org/10.1086/656918 


\section{Appendix I: Questionnaire}

This questionnaire is aimed at assessing the demographic and risk factors that can lead to cytomegalovirus infection.

My name is, Nchagwa Edward, an MSc student in the department of Medical Laboratory Science, School of Medicine. I am investigating the demographic and risk factors that can lead to acquisition of cytomegalovirus. I kindly request you to fill the questionnaire below to the best of your knowledge.

Respondent code Gender: male ( ) female ( )

Date of interview

Classification of Subjects: Case ( ) Control ( )

SECTION A: DEMOGRAPHIC INFORMATION

Age: Below 2 years ( ); 2 - 12 years ( ); 13 - 24 years ( ); 25 - 44 years ( )

45 - 54 years ( ); 55 - 64years ( ); 65 years and above ( )

Marital status: Single ( ); Married ( ); Widowed ( ); Divorced ( ) others ( )

If others, Specify

Education level: None ( ); Primary ( ); Secondary ( ); Post-secondary ( )

Current occupation: Unemployed ( ); Casual ( ); Formal ( )

Economic status

(Monthly income < Kshs.23670 low, > Kshs.23671-120000 middle class, >120,000 upper)

Low income earner ( )

Middle income earners ( )

Upper income earners ( )

SECTION B: RISK FACTORS

1) Sexual behaviour

a) Have you ever had any sexual contact; Yes ( ) No ( )

If yes classify; protected sex i.e. use of condom ( ) non protected sex ( )

2) Sexual transmitted infection

a) Do you have or ever had any other sexual Transmitted disease? Yes ( ) No ( )

3) Circumcision (males)

a) Are you circumcised? Yes ( ) No ( )

If Yes, specify Traditional ( ) Hospital ( )

4) Group living situation and sharing of injections

a) Do you live in any one of the following places?

Camps, Home care, street; Yes ( ) No ( )

b) Are you an injection drug user? Yes ( ) No ( )

If, yes do you share the needles? Yes ( ) No ( )

5) Saliva-sharing behaviours

a) Do you share the following?

Drinks; Yes ( ) No ( )

Toothbrushes; Yes ( ) No ( )

Lip balm; Yes ( ) No ( ) 
b) Do you engage in kissing activity? Yes ( ) No ( )

6) Exposure to young Children at Home

a) Do you care for the young one at home (Changing diapers, feeding children, and looking after young children); Yes ( ) No ( )

7) Breast feeding (Below 18 Months)

a) Is the child breast feeding Yes ( ) No ( )

b) Do you wash hands after changing diapers? Yes ( ) No ( )

8) Immunocompetence

a) Do you have or ever had any of the following disease conditions (Diabetes, cancer, leukaemia, lymphoma or any known autoimmune disease); Yes ( ) No ( )

b) Have you ever had any organ transplant; Yes ( ) No ( )

9) Female

a) Are you pregnant? Yes ( ) No ( )

10)Blood Transfusion

a) Have you ever received any blood or blood product before? Yes ( ) No ( ) 